\title{
A Comparative Analysis of Regulatory Frameworks on Climate Change
}

\author{
Mabobane C. Sebopela
}

Kola O. Odeku

\author{
Faculty of Management and Law, University of Limpopo, Turfloop, South Africa
}

\section{Doi:10.5901/mjss.2014.v5n20p3078}

\begin{abstract}
This paper makes a modest comparison of regulatory interventions on climate change in India, South Africa and the United Kingdom. While India and South Africa, both developing countries are not mandated under the international regulatory frameworks on emissions reduction, the United Kingdom is under obligations to reduce its emissions. It highlights the importance of emissions reduction even by countries not compelled to reduce their emissions and points out what India and South Africa have done in this respect. It identifies lessons to be learnt and concludes that it is the responsibility of everybody, located in countries, with or without obligations to reduce emissions, to tackle global warming and climate change.
\end{abstract}

Keywords: Regulatory interventions, Emissions reduction, developed and developing countries, Responsibility, Climate change

\section{Introduction}

Even though South Africa is not under any international obligation to reduce its greenhouse gas emissions, (Babiker et al. 2000) South Africa has continually been using various initiatives which include but not limited to policies, measures, strategies, guidelines and so on to foster emissions reduction (Winkler, 2010). Regulatory interventions are important in order to bring down the heat that is causing global warming climate change and now destroying the atmosphere and the ecosystems in an unprecedented way. Changes in climate is affecting the entire economy as well as many sectors including energy, transport, agriculture, forestry, water resource management and provision of water services, and health (DEAT, 2004).

South Africa has therefore committed itself to continue to use all means available to reduce its emissions and it has now commence aggressive implementation of various mitigation and adaptation strategies through numerous interventions that are progressive, ambitious, and far-reaching (Meyer and Odeku, 2009).

The interventions are "policies to restructure the energy sector, stimulate economic development, increase access to affordable energy services, manage energy-related environmental impacts, and secure energy supply through diversification, as articulated in the government's 1998 "Energy White Paper" (Halsnæs and Verhagen, 2007). And also intensify effort on economic development and growth that will seek to use alternative sustainable energy in all sectors of the economy including the domestic side (Omer, 2008). Against this backdrop, massive investment in renewable energy and innovation in renewable energy technologies are being given huge consideration in the scheme of things especially when it comes to financing and investment (Banks and Schäffler, 2006).

South Africa has also developed both long term and short time strategies to reduce emissions (Roberts, 2008). The country aims at "three strategic options to avoid business as usual GHG emissions. In brief, the Framework establishes general guidelines for tackling climate change including the target of curbing the growth of GHG emissions by 2020-2025 at the latest; the introduction of a carbon tax, renewable energy feed-in tariffs, and a carbon capture and storage system; and mandatory targets for renewable energy, energy efficiency, and transport." (Davidson, 2002).

As aptly observed by the Eartlife (2014, "these measures are, in turn, the product of a broader policy context that gradually gave rise to the current climate change framework in South Africa. They started with the National Climate Change Response Strategy in 2004, which represents the first direct recognition of the need for action on climate change. Two years later, the Cabinet commissioned the Long-Term Mitigation Scenario (LTMS) study, in an attempt to produce sound scientific analysis from which the government could derive a long-term climate policy, on which it could base its international positions in the UNFCCC framework and with which it could persuade stakeholders to act. The LTMS produced a series of policy recommendations, which will be at the heart of South Africa's climate change legislation."

According to Earthlife Africa (2014) "the LTMS process was defined in two stages. First, the scenario building 
phase on research relating to carbon emissions, the potential for reductions and the economic implications defined in terms of the impact on GDP growth, employment and equity. Second the 'high level group' (HLG) process was to involve a 'dialogue' of the Inter-ministerial committee on climate change and 'leaders' from business, labour and civil society. The main focus of LTMS is on how South Africa can reduce emissions of GHG."

The LTMS includes different scenarios of mitigation action for South Africa and a technical report that is underpinned by technical inputs and research on energy emissions, non-energy emissions, and a macro-economic analysis (DEAT, 2007). The combination of the scenario document and the technical reports serve to inform long-term national policy and provides South Africa with a position in multilateral climate negotiations on a post- 2012 climate regime (Earthlife Africa, 2014). "Despite the fact that renewable energy sources are still at an embryonic stages in South Africa, where most of the energy matrix is coal-based, the government has been investing heavily in the promotion of renewable energy and energy efficiency." Accordingly, the National Energy Act 2008, Act no. 34 of 2008, is among other things, concerned with increasing the generation and consumption of renewable energy. The Act also created the South African National Energy Development Institute, responsible for promoting efficient generation and consumption of energy and energy research and development. The bulk of government action in this domain is translated into policies, strategies and regulations. Namely, the White Paper on the Promotion of Renewable Energy and Clean Energy Development, 2003; the Integrated Clean Household Energy Strategy, 2003, the Implementation Strategy for the Control of Exhaust Emissions from Road-going Vehicles in South Africa, 2003, the Renewable Energy Policy, 2004, the Cleaner Production Strategy 2005, the Energy Efficiency Strategy, 2005, the Biofuels Industrial Strategy, 2007, and Renewable Energy Feed-in Tariffs, 2009.

Explaining the dynamics of these scenarios Winkler and Marquand (2009) observe that "Climate change mitigation poses significant challenges for South Africa and its energy development, historically highly energy intensive. At the same time, the country faces a host of daunting development challenges, exacerbated by the legacy of apartheid. Examining both challenges, this paper considers how alternative conceptions of a development path can be achieved. In the short term, energy efficiency provides large potential for mitigation-and energy savings at the same time. Changing South Africa's fuel mix, dependent to three-quarters on coal, is at least a medium-term challenge. The minerals-energy complex is so central to the economy that it is likely to take decades to change dramatically. The most transformative change is to an alteration in economic structure, likely to take long to achieve."

While none of these regulations has the status of law, they set a series of meaningful national targets. For instance, the White Paper on Renewable Energy, 2003 requires that 10,000 gigawatt hours (GWh) of energy be derived from renewable energy sources (mostly from biomass, wind, solar and small-scale hydro) by 2013 (NERSA, 2009). The Energy Efficiency Strategy, 2005 sets the target of a 12\% energy efficiency improvement by 2015, which is to be met through the increased use and development of renewable energy. Of recent, as part of the strategy to diversify from fossil fuels, the government introduced "the National Energy Regulator of South Africa (NERSA) announced the implementation of Renewable Energy Feed-in Tariffs (REFITS) set to produce 10 TWh of electricity per year by 2013 to be paid for over a period of 20 years (Odeku et al. 2010). The number of selected technologies continue to increase as the country become progressive in technological innovations and breakthrough in alternative energy.

It is pertinent to point out that "the only legal instrument dealing directly with climate change in South Africa is the Taxation Law Amendment Bill of 2009, which amends the 1962 Income Tax Act to include, among other things, income tax incentives for participation in Clean Development Mechanism (CDM) projects as well as for energy efficiency savings" (Swart, 2012) . South Africa continues to set ambitious targets for itself in its bid to act responsibly and sustainably and these will, to a large extent achieve the goals ( Dodman, 2009).

\section{Indian Emissions Reduction Frameworks}

Nowadays, greenhouse gas emissions reduction is of high priority and various options are being used by countries to realize this ( Weisser, 2007). The study of Philibert and Pershing (2001) identified "five options for targets that could be taken by all countries to meet the ultimate objective of the climate change convention: fixed, binding targets; dynamic targets; non-binding targets; sectoral targets; policies and measures. Each is evaluated according to criteria of environmental effectiveness, cost-effectiveness, contribution to economic growth and sustainable development, and equity. While fixed, binding targets continue to be viable for industrialised countries, they do not seem suitable for many developing countries in the near future. Dynamic targets could alleviate developing countries' concerns about constraining their development as well as broader concerns about possible introduction of "hot air" in a world trading regime; they could also be considered for some or all industrialised countries. Non-binding targets could be politically 
appealing to developing countries, alleviate fears about development and/or hot air, but might only allow conditional participation in emissions trading by developing countries. Sectoral targets could offer a pragmatic first step-although their cost-effectiveness might be questioned. Finally, targets based on commitments to implement specific policies and measures might drive mitigation action and be part of negotiated packages including financial and technological cooperation. All these options may coexist in the future."

India as a country is a non-Annex I country under the Kyoto Protocol and thus has no binding target for emissions reduction (Philibert and Pershing, 2001). However, India is an active participant in the Clean Development Mechanism (CDM) established by the Protocol. It had more than 520 registered CDM projects as of 30th August, 2010. India has a number of policies that, while not driven by climate concerns, contribute to climate mitigation by reducing or avoiding greenhouse gas emissions (Sathaye and Shukla, 2006).

Rather than embrace or develop integrative binding legislation, India has developed a policy process to specifically address climate change (Baumert, 2006). India adopted its first 'National Action Plan on Climate Change' (NAPCC) in 2008, outlining existing and future policies and programmes directed at climate change mitigation and adaptation. The plan outlines eight "national missions" running up to 2017 ( Sharma, 2010). These missions include the National Solar Mission, the National Mission for Enhanced Energy, Efficiency, the National Mission on Sustainable Habitat National Mission for a Green India aiming at increasing the forest cover and the National Mission on Strategic Knowledge aiming at establishing a research fund. In addition, it contains adaptation missions such as the National Mission for Sustaining the Himalayan Ecosystem to help protect India's water supply from the Himalaya and the National Mission for Sustainable Agriculture (Ling, 2012).

In June, 2010, the Ministry of Environment and Forests of India released its document called India: 'Taking on Climate Change - Post Copenhagen Domestic Actions'. In addition to evaluating the progress of the policies announced in the 2008 NAPCC, it stated that India would be the first developing country to publish its emissions inventory in a twoyear cycle going forward. It has started by publishing its 2007 inventory (Chitre, 2011). In addition, India has also announced a levy, which will apply to both domestically produced and imported coal. This money will go into a National Clean Energy Fund that will be used for funding research, innovative projects in clean energy technologies, and environmental remedial programmes. The Government of India had set up an Expert Group on Low Carbon Strategy for Inclusive Growth. The Group had been given the mandate to develop a roadmap for India for low carbon development. The Group's recommendations became a central part of India's 12th Five-Year Plan that came into effect in 2012 (Pahuja et al. 2014).

India has made important efforts in the last two decades to reduce its energy intensity ( Asif and Muneer, 2007). Factors contributing to the decline in energy intensity include improved energy efficiency, increased use of renewable and nuclear power, expanded public transport, and energy pricing reform (Nanda, 2010).

The Electricity Act Act 36 2003, sought to improve the coordinate development of the power sector in India. As an objective, it seeks to promote efficient and environmentally benign policies, among others. The Act recognised the role of renewable energy in the country's National Electricity Policy (issued by the government in 2005) and contains key provisions relating to renewable energy. This Act was supplemented by the 2006 Tariff Policy that stipulates that State Electricity Regulatory Commissions (SERCSs) must purchase a minimum percentage of power from renewable sources. The 2006 Integrated Energy Policy that received Cabinet approval in 2008 has the broad objective of meeting energy demand "at the least cost in a technically efficient, economically viable and environmentally sustainable manner." It contains a number of policies that contribute to avoiding GHG emission. In 2007, India's cabinet made a series of announcements regarding ethanol production and proposed an indicative target of $20 \%$ blending of biofuels, both for biodiesel and bio-ethanol by 2017.

In addition to these framework policies, there are important numbers of regulation and incentive instruments promoting energy efficiency and the use of renewable energy at the Federal and the State levels. These include a revision in 2007 of the Energy Conservation Building Code that sets minimum requirements for building envelope components, lighting, electrical system, water heating and pumping systems. Solar and wind power are strongly promoted as well through Solar and Wind Power Generation Based Incentives (Sawin, 2006). As announced by the NAPCC, the National Solar Mission is a large-scale solar energy programme that will run from 2010 to 2022. It promotes electricity generation from both small and large-scale solar plants.

India's legislative processes are empowered by the provisions of India's constitution regarding the environment and climate change (Jasanoff, 1993). According to Article 48A in the Constitution of India 1949. Article 48A requires the state to protect and improve the environment and to safeguard the forests and wildlife of the country. Article 51A enumerates the fundamental duties of citizens of India. These duties encompass the responsibility to protect and improve 
the natural environment including forests lakes, rivers, and wildlife, and to have compassion for living creatures, Article 48A in The Constitution Of India 1949 (India constitution. part IVA, art, $51 \mathrm{~A}(\mathrm{G})$. Article 21 states that no person shall be deprived of his life or personal liberty except according to procedure established by law (Rosencranz and Rustonjee, 1995). This due process provision has been interpreted to include an implied and environmental protection by Indian courts (India constitution art 21).

Apart from the above mentioned legislations, India proceeded to issue policies in respect of the fight against the global phenomenon. These include National Mission for Enhanced Energy Efficiency Policy (the plan recommends mandating specific energy consumption decreases in large energy-using industries, including a system for companies to trade energy-saving certificate (Bora, 2008). It also focuses on the role of incentives, based on Energy Conservation Act), National Mission on Sustainable Habitat (seeks to promote energy efficiency as an essential component of urban planning. It calls for extending the energy Conservation Building Code, and emphasises urban waste management and recycling, including power production from waste), National Mission on Strategic Knowledge of Climate Change( this mission is for the establishment of a Climate Science Research Fund, improved climate modelling capacities, and increased international collaboration) and National Mission for Sustainable Agriculture(this aims to support adaptation to climate change in agriculture, through the development of climate-resilient crops and adapted agricultural practices, as well the expansion of weather insurance mechanisms) (Pandve, 2009).

In line with the above, the right to food was never overlooked as the concept of food security is largely affected by climate change and environmental degradation.

\section{Regulatory Framework on Climate Change: United Kingdom}

The UK has developed several instruments directly aimed at achieving emissions reduction since the early 2000s (Collier, 2002). In 2001, it introduced a Climate Change Levy that applies to electricity, gas, solid fuel and liquefied gases used for lighting, heating and power in the business and public sectors. Complementing the levy, under the Climate Change Agreements that took effect in 2001, energy intensive business users are allowed to receive an $80 \%$ discount from the Climate Change Levy if they meet energy efficiency or carbon saving targets (Barker et al. 2007). This measure was extended in time and sectors concerned in 2004 and 2007 (Socolow, 2006).

In 2006, the publication of the Climate Change Programme outlined all of the UK policies and programmes in place to tackle climate change, including several measures relating to energy efficiency (Okereke, 2007). The 2006 Programme included a package of new and existing measures, which were projected to reduce $\mathrm{CO}_{2}$ emissions to $15-18 \%$ below 1990 levels by 2010 and work towards the longer term goal to reduce $\mathrm{CO}_{2}$ emissions by $60 \%$ by 2050, as set out in the Energy White Paper (2003).

On 21 June, 2006, the UK government also approved the Climate Change and Sustainable Energy Act, which placed an obligation on the Department for Environment, Food and Rural Affairs (Defra) to report to parliament on greenhouse gas emissions in the UK and actions taken by government to reduce these emissions. The first report was put to the UK parliament on 26 July, 2007 ( Strachan and Kannan, 2008). The legislation also established a scheme to promote national targets for micro-generation and for reporting on the energy efficiency of residential accommodation (Anable and Shaw, 2007).

The UK flagship legislation on climate change is the 2008 Climate Change Act. It provides a long-term framework for improving carbon management, to help the transition to a low carbon economy, encourage investment in low carbon goods and provides an international signal. It put the UK's ambitious emissions reduction target into legislation (at least 80\% below 1990 levels by 2050), created five-yearly 'carbon budgets' and set up the independent Climate Change Committee to advise the government (Bolton and Hawkes, 2013).

In March, 2009, the Climate Change Act Impact Assessment was updated to reflect the final contents of the Act (Wende et al. 2012). The 2009 UK Low Carbon Transition Plan is a White Paper outlining how the British economy will be transformed to ensure the UK meets its emission reduction targets ands its first three five-year carbon budgets that were set in law in May, 2009 ( Foxon, 2013). The paper sets out the Government's long-term strategy to radically cut the nation's carbon emissions by 2020.

Most recently, the new coalition government has proposed an Energy Bill. The Bill has three principal objectives: tackling barriers to investment in energy efficiency; enhancing energy security; and enabling investment in low carbon energy supplies. This bill was introduced to the House of Lords on 8 December, 2010 and had its first reading in the House of Commons on 15 March, 2011 ( Wood and Dow, 2011).

UK highlighted the challenges in meeting the growing demand for energy whilst reducing emissions to prevent 
significant damage from climate change (Bradshaw, 2010). The IEA projects $70 \%$ increase in energy demand in the next 25 years (Yergin, 2006). To meet the target of global temperature not exceeding more than $2^{\circ} \mathrm{C}$ at least 15 per cent emission reduction would be required by 2050 (Hepburn and Stern, 2008). The UK representative opined that a number of technological options for reducing emissions at reasonable costs over the long term already exist (Benedick and Benedick, 2009). Some of the options may be well established while others may need further exploration or feasibility analysis. If these are applied as a portfolio of options, they may prove to be more effective. Delays in action would result into deeper emission reductions at a later date. These would increase the costs and the emissions may even reach irreversible levels.

\subsection{Mitigation strategy in United Kingdom}

In the United Kingdom, the Carbon Trust, established in 2001 with government funding, has promoted the concept of the "carbon footprint" (Bumpus and Liverman, 2008 ). By undertaking a carbon investigation of their supply chains, all businesses can minimize the carbon emitted at every stage of a product's life cycle, from source to shelf, consumption and disposal (McKinnon, 2010). The total amount of carbon emitted to arrive at a final product is that product's carbon footprint.

\section{Lessons for South Africa}

Although South Africa and India are non-Annex I country under the Kyoto Protocol and thus has no binding target for emissions reduction ( Babiker et al. 2000), there are a number of actions taken by India and United Kingdom that South Africa could learn from.

\subsection{Governance}

Climate change issues are prioritise in the UK and India and the government play active roles in virtually all issues relating to emissions reduction. This indicates buy-in at the highest level and encourages action at lower levels. The two countries address climate change at sub-national levels, for example in India, each State has to develop a State Action Plan on Climate Change

\subsection{Finance and Trading}

India has set up national funds to finance climate change activities. India has also introduced a tax on imported and domestic coal which supports the Clean Energy Fund (Ottinger and Williams, 2002). India has, after introducing feed-in tariffs, found that reverse auction actually worked far better ( Altenburg and Engelmeier, 2013), and this model may be implemented in other countries like South Africa to encourage private sector involvement.

\subsection{Private Sector}

India has programmes to encourage the private sector to take action. India's Energy Conservation Awards have resulted in USD 2.6 billion energy cost savings for their biggest industries and emissions reductions for the country (McNeil, 2011).

\subsection{Mitigation}

India has become world leaders in renewable energy challenging the US and Germany ( Lewis and Wiser, 2007). It has shown that developing countries can produce and operate green energy systems and that a lower carbon development pathway is possible (Demirbas et al. 2009). As a result, South Africa may learn from the Indian legislations on how to mitigate climate change.

\section{Conclusion}

To some extent, South African and Indian interventions are merely through policies which might not even be implemented 
if the administrative and political wills are not there. The approach of the UK seems very important and talks to the issues of enforcement. More importantly, apart from the law, there are different committees which regularly meet on the issues of global climate change. South Africa can learn a lot of approaches from the UK and India with regard to governance, mitigation, financing, adaptation and so on.

\section{References}

AltenburgT, Engelmeier T 2013. Boosting solar investment with limited subsidies: Rent management and policy learning in India. Energy Policy, 59: 866-874.

Anable J, Shaw J 2007. Priorities, policies and (time)scales: the delivery of emissions reductions in the UK transport sector. Area, 39(4): 443-457.

Asif M, Muneer T 2007. Energy supply, its demand and security issues for developed and emerging economies. Renewable and Sustainable Energy Reviews, 11(7): 1388-1413.

Babiker M, Reill JMy, Jacoby HD 2000.The Kyoto Protocol and developing countries. Energy Policy, 2898): 525-536.

Babiker M, John M Reilly, Henry D Jacoby 2000. The Kyoto Protocol and developing countries. Energy Policy. 28(8): 525-536.

Banks D, Schäffler J 2006. The potential contribution of renewable energy in South Africa. From http://projects.gibb.co.za/Portals/3/ projects/201002\%20Nuclear\%201/Appendix\%20D\%20Public\%20Participation/App\%20D8/potential\%20of\%20RE\%20in\%20SA\% 20Feb06.pdf. (Retrieved on 21 March, 2014).

Barker T, Ekins P, Foxon T 2007. Macroeconomic effects of efficiency policies for energy-intensive industries: The case of the UK Climate Change Agreements, 2000-2010. Energy Economics. 29(4): 760-778.

Baumert K A 2006. Participation of Developing Countries in the International Climate Change Regime: Lessons for the Future, George Washington International Law Review, 38: 365-376.

Benedick RE, Benedick RE 2009. Ozone diplomacy: New directions in safeguarding the planet. From http://books.google.co.zal books?hl=en\&lr=\&id=twjbcjn-=gbelvxonkx\&sig=qvrn6rpbtwiiv4nbmf81kk8bjqa\#v=onepage\&q\&f=false. (Retrieved on 12 September, 2013).

Bolton R, Hawkes A 2013. Infrastructure, investment and the low carbon transition. Palgrave McMillan, New York, USA.

Bora K 2008. International centre for promotion of enterprises (icpe), ljubljana. From http://www.cek.ef.uni-lj.si/magister/bora134-b.pdf. (Retrieved on 5 November, 2013).

Bradshaw MJ 2010. Global energy dilemmas: a geographical perspective. The Geographical Journal, 176(4): 275-290.

Bumpus AG, Liverman DM 2008. Accumulation by Decarbonization and the Governance of Carbon Offsets. Economic Geography, 84(2): 127-155.

Chitre SP 2011. India's Role in an International Legal Solution to the Global Climate Change Problem. From http://papers.ssrn.com/sol3/ papers.cfm?abstract_id=1802862. (Retrieved on 4 February, 2014).

Collier U 2002. EU energy policy in a changing climate. From http://books.google.co.za/books?hl=en\&lr=\&id=fyivu4etytkc\&oi=fnd\&pg= =gnzf1kuivi\&sig=b_y4lystvrvput-tgqu0vicdex4\#v=onepage\&q\&f=false. (Retrieved on 2 September, 2013).

Davidson 0 2002. Development Objectives Implementation Measures Reductions from Projected Emissions Source: Estimates by Energy \& Development Research Centre, University of Cape Town, South Africa.

DEAT 2004. Department of Environmental Affairs and Tourism, a National Climate Change Response Strategyfor South Africa. From http://unfccc.int/files/meetings/seminar/application/pdf/sem_sup3_south_africa.pdf. (Retrieved 23 June, 2014).

DEAT 2007. Long Term Mitigation Scenarios South Africa. Department of Environmental Affairs and Tourism. From http://www.eri.uct.ac .za/Research/publications/07Scenario_team-LTMS_Scenarios.pdf. (Retrieved on 25 April, 2014).

Demirbas MF, Balat M, Balat H 2009. Potential contribution of biomass to the sustainable energy development. Energy Conversion and Management, 50(7): 1746-1760.

Dodman D2009. Blaming cities for climate change? An analysis of urban greenhouse gas emissions inventories. Environment and Urbanization, 21(1): 185-201.

Earthlife Africa 2014. Johannesburg, Climate Change, Development and Energy Problems in South Africa: Another World is Possible. From http://Inw.creamermedia.co.za/articles/attachments/19745_oi_climate_change_south_africa.pdf (Retrieved 2 April, 2014).

Foxon TJ 2013. Transition pathways for a UK low carbon electricity future. Energy Policy, 52: 10-24.

Halsnæs K, Verhagen J 2007. Development based climate change adaptation and mitigation-conceptual issues and lessons learned in studies in developing countries. Mitigation and Adaptation Strategy for Global Change, 12:665-684.

Hepburn C, Stern N 2008. A new global deal on climate change. Oxford Review of Economic Policy, 24 (2): 259-279.

Jasanoff S 1993. India at the crossroads in global environmental policy. Global Environmental Change, 3(1): 32-52.

Lewis JI, Wiser RH 2007. Fostering a renewable energy technology industry: An international comparison of wind industry policy support mechanisms. Energy Policy, 35(3): 1844-1857.

Ling FH 2012. Sectoral policies for GHG Mitigation in Asia. From http://books.google.co.za/books?hl=en\&lr=\&id=6tbs 03zxwic\&oi=fnd\&pg=pa98\&dq= b8thjebg4x\&sig=54iy9-5xfnrerwvreudjwh0yek8\#v=onepage\&q\&f=false. (Retrieved on 16 July, 2014).

McKinnon AC 2010. Product-level carbon auditing of supply chains: environmental imperative or wasteful distraction? From http://www.emeraldinsight.com/doilfull/10.1108/09600031011018037. (Retrieved on 12 April, 2013). 
McNeil MI 2011. DSM Electricity Savings Potential in the Buildings Sector in APP Countries. From https://escholarship.org/ uc/item/8vc5007g. (Retrieved on 16 March, 2013).

Meyer E, Odeku K 2009. Climate Change, Energy, And Sustainable Development: Developing The African Continent at the Crossroads. Sustainable Development Law \& Policy Journal, 10(2): 51-55.

Nanda A D. 2010. India's Environmental Trump Card: How Reducing Black Carbon through Common but Differentiated Responsibilities Can Curb Climate Change, Denver Journal of International Law \& Policy, 39: 523-533.

NERSA 2009. NERSA's Feed-in Tariff: Will It Work for SA? From http://www.25degrees.net/index.php?option=com_zine\& view=article\&id=295:nersas-feed-in-tariff-will-it-work-forsa\&ltemid. (Retrieved on 16 March, 2014).

Odeku KO and Meyer EL, Mireku O, Letsoalo J L H 2010. Implementing a Renewable Energy Feed-in Tariff in South Africa: The Beginning of a New Dawn. Sustainable Development Law \& Policy Law, 11(2): 45-49.

Okereke C 2007. An Exploration of Motivations, Drivers and Barriers to Carbon Management: The UK FTSE 100. European Management Journal. 25(6): 475-486.

Omer AM 2008. Energy, environment and sustainable development. Renewable and Sustainable Energy Reviews. 12(9): 2265-2300.

Ottinger R L, Williams R 2002. Renewable Energy Sources for Development. Environmental Law, 32: 331-342.

Pahuja N, Pandey N, Mandal K 2014. GHG Mitigation In INDIA: An overview of the current policy landscapE. From http://mitigationpartnership.net/sites/default/files/wri_workingpaper_india_final.pdf. (Retrieved on 14 September, 2014).

Pandve HT 2009. India's National Action Plan on Climate Change. From http://www.ncbi.nlm.nih.gov/pmc/articles/PMC2822162/. (Retrieved on 16, September, 2013).

Philibert, C, Pershing J 2001. Considering the options: climate targets for all countries. Climate Policy. 1(2): 211-227.

Roberts D 2008. Thinking globally, acting locally_institutionalizing climate change at the local government level in Durban, South Africa. Environment and Urbanization, 20(2): 521-537.

Rosencranz A, Rustonjee S 1995. Citizens Right to a healthful environment. Environmental Policy \& Law, 25:324-335.

Sathaye J, Shukla PR 2006. Climate change, sustainable development and India: Global and national concerns. From http://agricoop.nic.in/Climatechange/ccr/files/Climate\%20Change\%20and\%20Sustainable\%20Development-India.pdf. (Retrieved on 20 February, 2014).

Sharma D 2010. Mainstreaming climate change adaptation in Indian cities. Environment and Urbanization, 22(2): 451-465.

Socolow R 2006. Stabilization Wedges : An elaboration of Concept. In Schellnhuber H J, W Cramer, N Nakicenovic, T Wigley and G Yohe (eds.) Avoiding dangerous climate change. Cambridge: Cambridge University Press.

Strachan N, Kannan R 2008. Hybrid modelling of long-term carbon reduction scenarios for the UK. Energy Economics, 30(6): 29472963.

Swart, K 2012. The Mining Legacy in South Africa-A Superfund Sized Problem or a Trust Fund Baby? From http://uctscholar.uct. ac.za/PDF/76906_Swart_A.pdf. (Retrieved on 23 August, 2014).

Weisser D 2007. A guide to life-cycle greenhouse gas (GHG) emissions from electric supply technologies. Energy, 32(9): 1543-1559.

Wende W, Bond A, Bobylev N, Stratmann L 2012. Climate change mitigation and adaptation in strategic environmental assessment. Environmental Impact Assessment Review, 32(1): 88-93.

Winkler H 2010.Taking action on climate change: Long term mitigation scenarios for South Africa. Juta \& Coy, Ltd, Cape Town, South Africa.

WInkler H, Marquand A 2009, Changing development paths: From an energy-intensive to low-carbon economy in South Africa. Climate and Development, 1(1): 47-65.

Wood G, Dow S 2011. What lessons have been learned in reforming the Renewables Obligation? An analysis of internal and external failures in UK renewable energy policy. Energy Policy, 39(5): 2228-2244.

Yergin D 2006. Ensuring Energy Security. Foreign Affairs, 85(2): 69-82. 